\title{
Bildung e método: notas sobre Hegel e Goethe
}

\author{
Bildung and method: notes about Hegel and Goethe
}

Rafael Marino ${ }^{1}$

\begin{abstract}
1 Doutorando e Mestre em Ciência Política pela FFLCH/ Universidade de São Paulo, graduado em Ciências Sociais pela USP, Brasil. E-mail: rafael.marino50@gmail.com http://lattes.cnpq.br/6940493917341785 (iD) http://orcid.org/0000-0002-2659-6434
\end{abstract}

\begin{abstract}
RESUMO: neste artigo pretende-se trabalhar com alguns elementos do método em Hegel, mais especificamente aqueles da sua Fenomenologia do espirito, e da literatura de Goethe, lançando mão, principalmente, de Os anos de aprendizado de Wilhelm Meister, com o fito de mostrar semelhanças importantes entre a forma do romance goethiano e a forma filosófica do texto hegeliano. Para tal, privilegiaremos a relação de ambos os livros com a formação, ou bildung. Com este propósito abordaremos: i) uma pequena introdução sobre o tema; ii) uma breve revisão sobre o conceito de Bildung na cultura alemã; iii) algumas notas sobre o romance de formação ou Bildunsgroman; iv) alguns pontos sobre o método hegeliano e sua relação com a Bildung; v) considerações finais as quais retomam o que fora sedimentado sobre o tema, aproximando Hegel e Goethe.

Palavras-chave: Filosofia alemã. Pensamento político e social alemão. Literatura alemã. Bildung (formação). Dialética.
\end{abstract}

\begin{abstract}
Hegel, more specifically from his book Phenonology of spirit, and the literature of Goethe, making use of, mainly, from Wilhelm Meister's Apprenticeship, whose purpose is to show important similarities between the form of the Goethian novel and the philosophical form of the Hegelian text. In order to do so, we will privilege the relationship of both books with formation orBildung. With this purpose we will address: i) a short introduction on the subject; ii) a brief review on the concept of Bildung in german culture; iii) some notes about the formation novel or Bildungsroman; iv) some points about the Hegelian method and its relation to Bildung; v) final conclusions which resume what had been settled on the theme, bringing Hegel and Goethe closer to each other.

Keywords: German philosophy. German political and social thought. German literature. Bildung (formation). Dialectic.
\end{abstract}

\section{INTRODUÇÃO}

Neste artigo pretendemos trabalhar com alguns pontos do método em Hegel, mais especificamente em sua Fenomenologia do Espírito, e da literatura goethiana, lançando mão, principalmente, de Os anos de aprendizado de Wilhelm Meister, privilegiando as suas relações com a formação, ou, como ficou consagrado nas ciências humanas - humanismo como gostaria Gadamer em seu livro Verdade e Método (GADAMER, 2013)- a Bildung.

Há algumas dificuldades em se tratar do método especulativo do filósofo alemão, já que seria "capaz de pensar a partir da própria coisa, de se entregar por assim dizer de modo passivo ao seu próprio conteúdo" (ADORNO, 2013, p. 77) ${ }^{1}$. À diferença de um Descar-

\footnotetext{
1 Tal postura também dá notícias, mais de um século depois, em uma realidade também atrasada dentro do Capitalismo, com Antônio Candido e Roberto Schwarz. Este mesmo dizia que a força de intervenção do programa dialético depende de "que ele seja posto em prática de fato, e não fique em fórmulas rituais" (SCHWARZ,2012, p. 130). Atraso alemão de que falava Marx (2011, p. 145-159) e muito bem explorado por Paulo Eduardo Arantes (1996) em seu Ressentimento da Dialética, que segundo Ruy Fausto seria "uma espécie de história social da dialética 'negativa', e do seu desfecho, a dialética hegeliana, dialética positiva, que opera uma 'negação da negação'. [...] A 'dialética negativa' - Arantes mostra, contra Adorno, que a noção se encontra em Hegel -corresponderia às experiências da 
tes que expos, na segunda parte de seu Discurso do método, quatro regras do método filosófico (DESCAR'TES, 2009). Exposição que se deu de modo 'desencarnado', algo que não seria comum em Hegel e sua filosofia não muito afeita a definições. ${ }^{2}$ Além disso, existem também os impasses de se lidar com a complexa literatura de Goethe e o livro supracitado, cuja consecução se dará com o apoio de críticos e críticas imersos no tema. De todo modo, tentaremos lidar com essas tensões ao longo do texto e expor alguns pontos da relação entre método, literatura e a Bildung.

\section{SOBRE A PERGUNTA: O QUE QUER DIZER BILDUNG?}

Gadamer, em seu livro Verdade e Método, diz que alguns conceitos que o humanismo e as ciências humanas tomariam como conceitos familiares guardam, na verdade, um grande

sofistica, da dialética antiga, do ceticismo, da conversação ilustrada do século XVTII (principalmente na figura 'cínica' do 'sobrinho de Rameau' de Diderot), da ironia romântica e também ao radicalismo dos inícios do idealismo alemão. Ela é lida em conexão com a emergência da figura do letrado independente e 'não orgânico' em contraposição à do 'clerc' medieval [...] sobredeterminada pela marginalidade sui-generis a que era condenado o intelectual em países atrasados como a Alemanha" (FAUSTO, 1997, p. 201).

${ }^{2}$ A não ser na conversa que teve com Goethe, legada a nós, por Eckermann: "Hegel, por quem Goethe nutre uma grande estima pessoal, embora alguns frutos brotados de sua filosofia não sejam de seu especial agrado, está aqui. Esta noite Goethe ofereceu um chá em sua homenagem, ao qual também esteve presente Zelter, que pretende partir ainda hoje. [...] Falou-se longamente a respeito de Hamman, e foi Hegel, sobretudo, quem deteve a palavra e exprimiu sobre aquele extraordinário espírito bem fundadas opiniões, que não poderiam ter surgido senão do mais sério e consciencioso estudo do objeto. [...]. A seguir, a conversa voltou-se para a essência da dialética. [...] No fundo - disse Hegel -, ela não é senão o espírito de contradição, regrado e metodicamente educado, que habita qualquer ser humano, um dom que mostra toda a sua grandeza na distinção entre o verdadeiro e o falso" (ECKERMANN, 2016, p. 627). potencial de desvelamento histórico, como o conceito de formação ou Bildung. Conceito cuja tradição, segundo o filósofo, poderia elucidar o que se faz nas ciências humanas de maneira muito melhor do que a ideia de método da ciência moderna (GADAMER, 2013, p. 54). Gadamer diz que tal conceito se origina na "mística da Idade Média ${ }^{3}$, sobrevive na mística do Barroco e sofre uma espiritualização com bases religiosas no 'Messias' de Klopstock, que abrange toda sua época, e, finalmente, na determinação fundamental de Herder, como 'formação que eleva à humanidade" (Ibid., p. 45). Já Wilma Maas afirma que Bildung "remonta ao médio-alto-alemão (bildunge, no alto alemão tardio bildunga). Seu primeiro significado está atrelado a acepções visuais como 'imagem' (Bild), reprodução, 'representação da imagem (Abbild, Ebenbild, 'imitação', 'reprodução' (Nachabmung, Nachbildung)" (MAAS, 2000, p. 25-26). A autora afirma que no decorrer do século XVIII há uma acentuação do primeiro significado de Bildung como 'forma', 'sobretudo 'formação' (Gestaltung), relacionada tanto à forma exterior, à conformação [...] como também à formação e desenvolvimento de características pessoais como intelecto, bons costumes, comportamento, através de influências exteriores" (Ibid., p. 26).

Ainda segundo Maas, a palavra em questão posteriormente ganhará um amplo leque de significados, sem perder funções semânticas antes atribuídas aos primeiros, havendo, em meados do século XVIII, uma forte apropriação deste conceito pelo discurso intelectual alemão. Apropriação - e vinculação do conceito ao contexto da Aufklärungt alemã - que

\footnotetext{
3 "Bildung (imaginatio) fazia parte do conjunto das quatro virtudes tradicionais, denominando a capacidade de representação interior e de autoinvestigação" (MAAS, 2000, p 27).

4 Aufklärung que teve a sua expressão canônica com Immanuel Kant, para quem: "Esclarecimento é a saída do ser humano de sua menoridade, menoridade essa na qual ele se inseriu por sua própria culpa. Menorida- 
tem seu testemunho mais claro no texto "Sobre a Pergunta: o que quer dizer esclarecer?" do filósofo Moses Mendelssohn, melhor evidenciado na seguinte passagem:

As palavras esclarecimento, cultura (Kultur), formação (Bildung), são ainda termos novos, recémchegados em nossa língua. Por ora, elas pertencem apenas à linguagem livresca. A multidão praticamente não as compreende. [...] Enquanto isso, o uso linguístico, que parece querer estipular uma diferença entre palavras de igual significado, ainda não teve tempo de estabelecer os limites para elas. Formação, cultura, esclarecimento são modificações da vida social; efeitos da diligência e dos esforços dos seres humanos por melhorar sua condição social. [...] Quanto mais a condição social de um povo for harmonizada com a determinação do homem, por meio da arte e diligência, mais formação terá esse povo. [...] A formação subdivide-se em cultura e esclarecimento. A cultura parece mais orientada para o elemento prático [...]. O esclarecimento, ao contrário, parece se relacionar mais com a dimensão teórica (MELDELSSOHN, 2011, p. 15-16).

Tal relato deixa clara a alta carga ideológica que o termo Bildung passaria a ter na Alemanha, "vinculado essencialmente aos pilares de sustentação do otimismo iluminista, como a crença na possibilidade de aperfeiçoamento pessoal e no trabalho em prol do bem comum". Conjuntamente, por meio dos autores pietistas, o sentido do termo formação passa a ser de construção do caráter do homem, tornando-se "predominante sobre o significado de Bildung como configuração de aparência exterior" (MAAS, 2000, p. 27). Ocorrendo mesmo certo retorno às concepções místicas

de é a incapacidade de se servir de seu próprio entendimento sem a condução de outrem. É-se culpado por tal menoridade, se a causa da mesma não se encontra na falta de entendimento, mas na falta de resolução e de coragem para se servir de seu próprio entendimento sem a condução de outrem. Sapere aude! Tenha a coragem de te servir de teu próprio entendimento! - este é, portanto, o lema do Esclarecimento" (KANT, 2011, p. $23-24)$. da Idade Média. No mesmo compasso Gadamer afirma que "a formação está estreitamente ligada ao conceito de cultura e designa, antes de tudo, a maneira especificamente humana de aperfeiçoar suas aptidões e faculdades" (GADAMER, 2013, p. 45). Nesse interim nos aproximamos de um dos sentidos do termo Bildungque será caro ao romance de formação (Bildungsroman): a concepção de processo. Processo entendido como uma "sucessão de etapas, teleologicamente encadeadas, que compõe o aperfeiçoamento do indivíduo em direção à harmonia e ao conhecimento de si e do mundo" (MAAS, 2000, p. 27). O conceito de formação passa então a dialogar com o que concebiam como Educação (Erz̧iehung), um outro conceito de suma importância para o Esclarecimento alemão e fundante do mundo burguês.

O referido conceito de Educação virá no bojo de um movimento que iniciará a educação moderna, na qual "a natureza humana passará a ser compreendida como passível de mudança e aperfeiçoamento" (Ibid., p. 28). Veiculando um projeto pedagógico fortemente iluminista em suas obras educativas, como no livro Emílio on Da educação de Jean-Jaques Rousseau. É importante salientar que mesmo com a proximidade, o termo educação é concebido mais comumente como uma ação dirigida, "com objetivos propedêuticos bastante definidos, ao passo que 'formação' (Bildung) 'pressupõe a atividade espontânea do indivíduo', ocorrendo ao longo do processo de auto aperfeiçoamento" (Ibid.).

Antes de passar para o tópico sobre o Bildungsroman, mais especificamente sobre $O s$ anos de aprendizado de Wilhem Meister, gostaria de inserir uma pequena consideração de Arantes (1996). Quando o referido autor passa do ciclo francês da inteligência europeia para o ciclo alemão, em seu livro Ressentimento da Dialética, diz passar também do radicalismo à ironia, ligado de certa forma ao atraso alemão e sua trama. Trama que traz em seu bojo "os sofri- 
mentos do jovem intelectual alemão", com Hegel mesmo, em sua introdução ao escrito sobre a Constituição da Alemanha, dirigindo-se "com clareza à bela alma infeliz da elite cultivada nacional, em particular à situação de 'morte permanente' do homem de Reflexão relegado ao pequeno 'mundo interior"', gestando uma espécie de "intelectual familiar cuja sorte está atrelada ao destino funesto do país" (ARANTES, 1996, p. 158). Funesto, pois atrasado. E em um registro também 'materialista', não posso deixar de lembrar, à sombra de outro autor, que, talvez, "a grande revolução de Marx tenha sido mostrar que as cambalhotas do Espirito não podem senão acompanhar as reviravoltas desencadeadas pelo movimento do capital [...]" (PATO, 2011, p. 52). Nesse sentido, uma experiência intelectual que possui uma forte relação com a grande importância atribuída ao conceito de Bildung em tal país, como fica claro na seguinte passagem:

Já o dissemos, tornamos a insistir, antes de retomar o assunto noutro capítulo: incluir o 'idealismo' - tanto na cultura quanto, em particular, o dos filósofos clássicos - no rol das ilusões compensadoras, forjadas pela consciência infeliz do atraso nacional, evidentemente não o explica. Em contrapartida tampouco o entenderemos em sua justa medida se ignorarmos suas origens intelectuais, isto é, se passarmos ao largo do fato elementar de que a centralidade da 'ideia' trai justamente a consagração compensatória do homem culto posto em evidência com zelo redobrado na circunstância adversa da defasagem histórica. Adversidade num certo sentido vantajosa, quanto mitigada por pequenas desforras, cuja soma culminava na entronização social da Bildung, em proporções desconhecidas em países onde a generalização da forma mercadoria alcançara os 'bens culturais"' (ARANTES, 1996, p. 175) $)^{5}$.

\footnotetext{
${ }^{5}$ É importante lembrar que para Paulo Arantes a dialética teria seus nexos materiais, sendo ela mesma digamos que histórica, nas palavras de Bento Prado: "De alguma maneira, Kojève atirou no que viu e acertou no que não viu: projetando arbitrariamente no livro de
}

Um trecho que pode trazer certa luz sobre a utilização constante do termo formação, passando mesmo a ser um termo chave para dar maior inteligibilidade ao ciclo intelectual alemão.

\section{NOTAS SOBRE BILDUNSGRO- MAN: OS ANOS DE APRENDIZA- DO DE WILHELM MEISTER}

Segundo as lições de Wilma Maas o romance de Goethe sobre Wilhelm Meister seria um "exemplo paradigmático de uma série de romances nos quais podem ser identificados os mesmos pressupostos que norteavam a literatura eminentemente educativa da $A u$ flärung” (MAAS, 2000, p. 29). Em tal romance

Hegel uma Gestalt dela ausente, teria posto a nu, sem querer, o nervo vivo da Dialética. Uma espécie de pressentimento obscuro da presença do intelectual (sempre oscilando entre mania e depressão) na própria essência da Dialética e que o livro Ressentimento da Dialética pretende expor (Darstellen seria mais bonito) em todas as suas complicadas mediações; pressentimento a ser explicado e levado às suas últimas consequências" (PRADO JR., 1996, p.11). Para Adorno o quadro do atraso - suas vantagens, talvez - e sua relação com a experiência intelectual hegeliana também não passou sem menção em seus estudos sobre a dialética hegeliana ou melhor, na formulação de um conceito novo de dialética: "Apenas hoje, cento e cinquenta anos depois, o mundo compreendido pelo sistema hegeliano é revelado literalmente como sistema, nomeadamente de uma sociedade radicalmente socializada, isso de modo diabólico. Um dos méritos mais notáveis da empreitada de Hegel é o fato de ela ter inferido, a partir do conceito, esse caráter sistemático da sociedade, muito antes que ele pudesse impor-se no campo acessível à experiência de Hegel, campo que era ainda este de uma Alemanha deveras atrasada no que se refere ao desenvolvimento social" (ADORNO, 2013, p. 103). E também em outro trecho: "No período primevo do idealismo, quando na Alemanha subdesenvolvida a sociedade civil ainda não tinha de formado como um todo, a crítica ao particular possuía outro tipo de dignidade. No campo teórico, idealismo significava a visão de que a soma dos saberes particulares não constituía o todo, que o melhor do conhecimento assim como do potencial humano escapava por entre as malhas da divisão do trabalho" (Ibid., p.144). 
pode ser vista a mediação entre a busca individual pelo aperfeiçoamento das qualidades intrínsecas do homem para o bem comum, e a sua realização efetiva. Ou como lembra Mazzari, a obra, dentro de sua riqueza infinda, teria dois princípios estruturantes:

[...] o primeiro, que se manifesta nos cinco livros iniciais do romance (que compõe a 'missão teatral de Wilhelm Meister'), consiste no conceito teleológico do desdobramento gradativo das potencialidades do indivíduo, no sentido de uma enteléquia humana, que o herói aspira cumprir exclusivamente no mundo dos palcos alemães. O segundo princípio assoma nos dois últimos livros, em seguida, e como contraponto, ao complexo pietista das 'Confissões de uma bela alma', e aproxima-se de uma espécie de 'teoria da socialização', preconizando-se a necessidade de interação estreita entre o indivíduo e a sociedade, 'eu' e o mundo - princípio que, visto de outra perspectiva, corresponde ao motivo de reconciliação do indivíduo problemático com a realidade -, ou então, nos termos de Hegel, à sua superação da discrepância entre a 'poesia do coração' e a 'prosa adversa das relações sociais" (MAZZARI, 2010, p. 108) ${ }^{6}$.

Maas vê ainda que em tal romance há uma passagem importante, pois haveria a passagem da cultura do "mérito transmitido, fundamentado nos direitos de posse e herança, para a cultura do mérito pessoal adquirido, atributo do burguês em formação" (MAAS, 2000, p. 30). Nesse sentido poderíamos ver uma afinidade do romance de Goethe com os pressu-

${ }^{6}$ Lembrando o benfazejo trecho de Hegel: "De uma maneira inteiramente diferente se passam as coisas como o romance, a moderna epopeia burguesa. [...] O romance, no moderno sentido, pressupõe uma efetividade já ordenada para a prosa, sobre cujo terreno ele novamente recupera em seu círculo de poesia - tanto que diz respeito à vitalidade do acontecimento quanto no que se refere aos indivíduos e seu destino -, até onde é possível nesta pressuposição, seu direito perdido. Uma das colisões mais apropriadas e mais comuns do romance é, por isso, o conflito entre a poesia do coração e a prosa oposta das relações, bem como da contingência de circunstâncias externas [...]" (HEGEL, 2004, p. 137-138). postos da literatura educativa do Esclarecimento alemão, veiculada, no livro, pela chamada Sociedade da Torre. Contudo o protagonista do livro ultrapassa, "porém, a instância relativamente limitada da concepção educativa da Sociedade da Torre, por meio de sua busca pela formação universal" (Ibid., p. 31). Com esse movimento vemos uma radicalização da distinção entre as concepções de 'formação' (Bildung) - usada preferencialmente "quando sua intenção era designar um processo de moldagem, de cultivo, mas também de desenvolvimento e auto aperfeiçoamento das faculdades espirituais e intelectuais do homem, do coração, do gosto" (VIERHAUS apud MAAS, 2000, p.37) - e de educação (Erziehung) como "um processo pedagógico que leva ao desenvolvimento das faculdades racionais do indivíduo" (MAAS, 2000, p. 37).

Continuando com o argumento, vemos que o 'nexo social' do romance seria uma vontade burguesa de autoaperfeiçoamento, entretanto o primeiro entrave para tal processo que o nosso protagonista irá encontrar é, justamente, a sua própria origem social e econômica. Meister mesmo lamenta a estreiteza de horizontes do destino burguês, contrapondo-o às possibilidades da aristocracia, destinada a "uma formação pessoal e universalizante, isto é, de acordo com seus talentos e habilidades natas, ao mesmo tempo que voltada para um repertório universal” (Ibid., p. 35)7. Como

\footnotetext{
7 "Para dizer-te uma palavra: instruir-me a mim mesmo, tal como sou, tem sido obscuramente meu desejo e minha intenção, desde a infância. Ainda conservo essa disposição, com a diferença de que agora vislumbro com mais clareza os meios que me permitirão realizálos. [...] Fosse eu um nobre e bem depressa estaria suprimida nossa desavença; mas, como nada mais sou do que um burguês, devo seguir um caminho próprio, e espero que venhas a me compreender. Ignoro o que se passa nos países estrangeiros, mas sei que na Alemanha só a um nobre é possível uma certa formação geral, e pessoal, se me permites dizer" (GOETHE, 2012, p. 284). E Maas argumenta ainda: "[...] Os sofrimentos do jovem Werther, de 1774, encontra-se essa mesma inadequação pessoal e profissional do protagonista ao 
registra na carta que manda para Werner (GOETHE, 2012, p. 284 - 287), a qual seria, para Mazzari:

[...] uma espécie de programa do 'romance de formação', uma vez que nela se formulam os motivos fundamentais da Autonomia (formarse a si mesmo), Totalidade (formação plena) e, ainda, Harmonia (a 'inclinação' irresistível' por formação harmônica). A expansão plena e harmoniosa das potencialidades do herói - artísticas, intelectuais, mas também físicas (Wilhelm confere grande importância à prática da esgrima) -, a realização efetiva de sua totalidade humana, são projetadas no futuro e sua existência apresenta-se assim como um 'estar a caminho' rumo a uma maestria de vida, que Goethe configura, todavia, menos como meta a ser alcançada do que como direção ou referência a ser seguida (MAZZARI, 2010, p. 113).

A título de comparação, Auerbach nos traz, do outro lado do Reno, um exemplo de formação total e sua relação com a situação econômica:

A situação social e econômica de Montaigne facilitou-lhe o formar-se e conservar-se por inteiro; o seu tempo, que ainda não tinha estabelecido totalmente, para as camadas mais altas da sociedade, os seus deveres, a técnica e o ethos do trabalho especializado, mas, muito pelo contrário, esforçava-se, sob a impressão da antiga civilização oligárquica, na procura de uma formação o mais ampla e humana possível, vinha ao encontro de suas necessidades (AUERBACH, 2013, p. 262).

Voltando a Meister vemos que esse romance coloca em circulação um conceito de formação mais elevado - uma formação universal, buscando sempre as possibilidades de desenvolver suas potencialidades para todos os la-

mundo estreito da burguesia, que move Wilhelm Meister para além do universo de origem. No Werther, obra comumente conhecida apenas como uma história do amor trágico, a incapacidade de adaptação ao universo burguês e suas convenções radicalizava-se, levando ao insucesso irrevogável, no plano pessoal e profissional" (MAAS, 2000, p. 36). dos - assentado na 'atuação viva' como queria Herder, ou nas palavras de Wilhelm Von Humboldt: "O verdadeiro objetivo do homem é a formação mais elevada e mais adequada de suas faculdades em um todo. A liberdade é condição imprescindível para essa formação" (HUMBOLDT apud MAAS, 2000, p. 38) ${ }^{8}$. Salvo engano, em sua Fenomenologia do Espirito o aspecto formativo se faz presente,

${ }^{8}$ Como coloca o próprio Hegel, referindo ao romance de Goethe em questão: "Trata-se, pois, de fazer um furo nesta ordem de coisas, modificar o mundo, melhorá-lo ou, a despeito dele, pelo menos recortar sobre a terra um céu: procurar a moça, tal como ela deve ser, encontrá-la e, então, ganha-la, conquistá-la e arrancá-la dos parentes perversos ou de outras relações nefastas. Mas estas lutas no mundo moderno nada mais são do que os anos de aprendizado, a educação de um indivíduo na efetividade presente, os quais alcançam, desse modo, seu verdadeiro sentido. Pois o fim de tais anos de aprendizado consiste no fato de que o sujeito aprende com a experiência, que ele se forma [hineinbildet] com seus desejos e opiniões nas relações subsistentes e na racionalidade destas, se insere no encadeamento do mundo e adquire nele um ponto de vista adequado. Por mais que alguém também tenha combatido o mundo, tenha sido empurrado para lá e para cá, por fim ele encontra, contudo, na maior parte das vezes sua moça e alguma posição, casa-se e também se torna um filisteu do mesmo modo que os outros; [...]. Aqui vemos o mesmo caráter da aventura, apenas que este encontra seu significado correto e o fantástico deve experimentar nisso a correção necessária" (HEGEL, 2014, p. 328-329). Ou mesmo Lukács: "A humanidade, como escopo fundamental desse tipo de configuração, requer um equilíbrio entre atividade e contemplação, entre vontade de intervir no mundo e capacidade receptiva em relação a ele. Chamou-se essa forma de romance de educação. Com acerto, pois a sua ação tem de ser um processo consciente, conduzido e direcionado por um determinado objetivo: o desenvolvimento de qualidades humanas que jamais floresceriam sem uma tal intervenção ativa de homens e felizes acasos; pois o que se alcança desse modo é algo por si próprio edificante e encorajador aos demais, por si próprio um meio de educação. A ação definida por esse objetivo tem algo da tranquilidade da segurança. Mas não se trata da tranquilidade apriorística de um mundo rematado; é a vontade de formação [bildung], consciente e segura de seu fim, que cria a atmosfera dessa inofensividade última" (LUKÁCS, 2009, p. 141-142). 
principalmente em dois momentos - que tem lá sua imbricação -, a saber quando "desenvolve a gênese de uma autoconsciência livre 'em si e para si' [...]" e quando mostra que "a essência do trabalho é formar a coisa, e não deformá-la" (GADAMER, 2013, p.48). Algo que exploraremos a seguir.

\section{ALgUNS PONTOS SOBRE MÉ- TODO E FORMAÇÃO}

Passaremos por alguns pontos da Fenomenologia que julgamos serem importantes para a compreensão das colocações posteriores, utilizando-nos principalmente da introdução de tal livro. Para Hegel, quando criticamos e examinamos as possibilidades de conhecimento, já conhecemos, algo que soaria um disparate para Kant, pois este dizia que o conhecimento começaria depois de um exame das faculdades do sujeito. Aquele julgava que a filosofia deste não era suficientemente crítica, visto que havia pressupostos que não tinham passado pelo crivo da crítica, ou, pelo 'tribunal da razão'. Pressupostos como a distinção radical, tomada como um dado, entre sujeito e objeto. Um dogmatismo que levaria ao não conhecimento da coisa mesma, mas apenas os seus efeitos em relação ao sujeito. Nesse sentido, Hegel pretende fazer com que a crítica se volte para ela mesma, a fim de apartar a filosofia de qualquer dogmatismo. Ou seja, radicalizando os princípios de Kant, não poderia aceitar a sua letra. Pretendendo, com essa crítica radical a todo e qualquer pressuposto, um ceticismo consumado. ${ }^{9}$ O filósofo alemão ainda diagnosti-

\footnotetext{
${ }^{9}$ Tal termo possui uma história interessante e com importantes reviravoltas, à maneira de sua real ascendência 'niilista' no cenário intelectual alemão, que poderia ser melhor acompanhado via Arantes, em seu artigo Nihilismusstreit, do qual tomaremos uma parte emprestada: "Trata-se de um niilismo por assim dizer filtrado pelo crivo do Conceito (cuja articulação entretanto não é indiferente, pelo contrário, à constelação fixada por tal designação) que, como nome de ceticismo chegou, chega ao centro nevrálgico do idealismo. [...]
}

ca um verdadeiro medo de errar por parte do criticismo, um medo que na verdade se funda em algo ainda maior: o medo de que tudo que tivesse conhecido seja falso, pois sujeito e objeto haviam sido radicalmente separados. Em outras palavras, um medo da verdade.

Ao mesmo tempo em que rejeita Kant, Hegel também deve rejeitar Fichte e Schelling, pois tanto aquele como este seriam também dogmáticos nas suas respectivas concepções de filosofia e ciência. Mais especificamente no ponto de partida de ambas, algo que tentaremos mostrar a partir dos seguintes trechos:

Suponha-se que a ciência seja um edifício; e que o fim principal desse edifício seja a firmeza. O fundamento é firme, e, tão logo ele esteja assentado, o fim estaria alcançado. Mas como no mero alicerce não se pode morar nem, apenas com ele, proteger-se, seja do assalto voluntário do inimigo, seja contra os assaltos involuntários das condições atmosféricas, edificam-se então sobre ele paredes laterais, e sobre estas um teto. Todas as partes do edifício são ajustadas com o fundamento e umas com as outras, e com isso o todo torna-se firme. Mas não se constrói um edifício firme para poder ajustar as partes: ajustam-se as partes para que o edifício se torne firme; e ele é firme na medida em que todas as suas partes repousam sobre um fundamento firme. [...] O fundamento é firme, e não está fundado em nenhum novo fundamento; está sobre a terra firme (FICHTE, 1993, p. 17).

O primeiro passo para a filosofia e a condição sem a qual nem sequer é possível entrar nela - é a compreensão de que o absolutamente ideal é também o absolutamente real, e de que, fora disso, só há, em geral, realidade sensível e condicionada, mas nenhuma realidade absoluta incondicionada. Aquele para o qual o absolutamente ideal ainda não se revelou como absolutamente real pode ser levado de diversas manei-

Consinta o leitor uma alusão sumária a tal distinção, de resto bem conhecida. Em poucas palavras: a filosofia entendamos, o discurso especulativo - não se atém ao resultado puramente negativo em que se detém o ceticismo, dimensão que entretanto conserva como a 'alma motora da progressão científica'” (ARANTES, 1996, p. 252). 
ras até esse ponto da compreensão, mas ela mesmo só pode ser aprovada indiretamente, não diretamente, pois é, pelo contrário, o fundamento e o princípio de toda demonstração (SCHELLING, 1993, P. 215).

Em primeiro lugar, para o nosso autor, a crítica deve se dar de modo imanente, com um exame que "não é só um exame do saber, mas também de seu padrão de medida." (HEGEL, 2012, p. 80). ${ }^{10} \mathrm{Em}$ que tomaríamos o objeto nele mesmo, sem uma violência externa proposta pelos autores expostos anteriormente -, no qual há a imputação de um padrão de medida exógeno à consciência natural. Outro ponto que seria inaceitável para Hegel nos trechos acima é que há um conceito de todo estático, que nada tem a ver com o conceito dialético. É preciso notar, com Adorno, que o filósofo reconhece a primazia do todo sobre as partes finitas, "que são imperfeitas e, em confrontação com o todo, contraditórias" (ADORNO, 2013, p. 78). Logo as partes não seriam tomadas autonomamente em relação ao todo, e sim que "o todo apenas se realiza por meio de suas partes, apenas como por meio da separação, alienação, da reflexão [...]" (Ibid., p. 74-75). Sendo assim poderíamos vislumbrar um conceito de todo que "somente existe de modo geral como a quintessência dos momentos parciais, que sempre apontam para além de si mesmos e se produzem uns a partir dos outros [...]" ou seja, "[...] ele não existe como algo para além deles" (Ibid., p. 75). Assim sendo, é de uma categoria de totalidade nada harmônica de que se trata ${ }^{11}$. Ademais, de

\footnotetext{
${ }^{10}$ É bom lembrar da advertência de Adorno, a fim de que não se confunda crítica imanente com alguma espécie de positivismo: "Hegel se curva em toda parte à essência própria do objeto, em toda parte o objeto é renovadamente imediato, mas mesmo essa subordinação à disciplina da coisa exige o mais extremo esforço do conceito" (ADORNO, 2013, p. 78).

${ }^{11}$ Seguindo raciocínio de Adorno sobre as mediação em Hegel, pode-se ver esta "nunca significa, como a pintou o mais desastroso desentendimento desde Kierkegaard, um meio entre os extremos, a mediação ocorre
}

modo algum toma o todo como a condição inicial da filosofia ${ }^{12}$, que iria tanto contra o espírito dialético - alérgico a definições a priori -, como seria um dogmatismo frente à consciência natural. Dois aspectos que explorarei a seguir, começando com as lições de Müller e Adorno:

O que caracteriza o conhecimento dialético é, primeiramente, que o verdadeiro (Hegel), o racional e concreto (Hegel, Marx), não são de acesso imediato a qualquer tipo de intuição intelectual ou experiência direta, que intuiria ou tomaria o objeto no seu ser dado imediato, mas que eles são o resultado de um movimento de pensamento, do que Hegel chama de 'trabalho do conceito', que expõe progressivamente, a partir das determinações mais simples e abstratas do conteúdo, suas determinações cada vez mais ricas, complexas e intensas, até o ponto de sua unidade, que não é uma unidade formal, mas uma unidade sintética de múltiplas determinações (MÜLLER, 1982, p. 22-23) 13.

Adorno também chama a atenção para a peculiaridade da noção de verdade em Hegel, digo peculiaridade já que comumente se atrela a noção de verdade ao fato imediato ${ }^{14}$, tentan-

através dos extremos e neles mesmo - esse é o aspecto radical de Hegel, que é irreconciliável com todo moderantismo" (ADORNO, 2013, p.79).

12 "Temos de partir daquela ideia do absolutamente ideal; nós o determinamos como saber absoluto, absoluto ato-de-conhecimento. [...]Um saber absoluto é apenas um saber tal que nele o subjetivo e o objetivo não são unificados como opostos, mas no qual o subjetivo inteiro e inversamente. Entendeu-se a identidade absoluta do subjetivo e do objetivo como princípio da filosofia, em parte, apenas negativamente (como mera não-diferença), em parte como mera vinculação de dois opostos em si em um terceiro que, aqui, deveria ser o Absoluto, e, em parte, ela ainda é entendida assim [...]. De modo geral, dever-se-ia, nessa designação da Ideia suprema, não pressupor o subjetivo e o objetivo, mas antes indicar que ambos, como opostos ou vinculados, devem ser concebidos, justamente, apenas naquela identidade" (SCHELLING, 1993, p. 217).

${ }^{13}$ Cf. (HEGEL, 2011, p. 49-62).

${ }^{14}$ Hegel a muito já insistia no contrário: “Aqui pode ser indicado, a partir do que foi dito, que não existe nada, nem no céu, nem na natureza ou no espírito ou seja lá 
do, a qualquer custo, afastar o sujeito e a subjetividade disto ${ }^{15}$. Segundo Adorno, para o filósofo alemão a verdade não seria mera adequatio entre o objeto e o juízo, como também não é um "predicado do pensamento subjetivo, mas deve se elevar substancialmente para além disso, precisamente como um 'em si e para si" (ADORNO, 2013, p. 113). Para Hegel, o saber da verdade não é menos que o saber do absoluto, portanto vê de maneira crítica o criticismo kantiano que dividia radicalmente o em si e a subjetividade. Seguindo Adorno, Hegel claramente se insurge contra o que chama de 'positivismo', mas faz isso sem cair num mero subjetivismo - "cuja preocupação exagerada em saber se também a verdade seria suficientemente verdadeira culmina na supressão da própria verdade" (Ibid., p.114) -, já que na ideia hegeliana da verdade, "o momento subjetivo, aquele do relativismo, é ultrapassado quando toma consciência de si mesmo. O pensamento está contido no verdadeiro, embora não seja idêntico a ele" (Ibid., grifos nossos). E aqui temos um momento em que verdade e dialética ${ }^{16}$ imbricam-se:

onde for, que não contenha imediatamente a imediaticidade bem como a mediação, de modo que essas duas determinações se mostrem inseparadas e inseparáveis e aquela oposição como algo nulo" (HEGEL, 2011, p. 50).

${ }^{15}$ Adorno na mestra trilha de Hegel nos lembra que: “O pensamento que, em total oposição à filosofia da identidade, é absolutamente desprovido de relação, o pensamento que retira do objeto toda participação do sujeito, toda 'ocupação', todo antropomorfismo, é a consciência do esquizofrênico. Sua objetividade triunfa num narcisismo patológico" (ADORNO, 2013, p. 119).

${ }^{16}$ Hegel mesmo nos lembra: "Contra tal posição deve-se afirmar que a verdade não é uma moeda cunhada, pronta para ser entregue e embolsada sem mais. Nem há um falso, como tampouco há um mal. 0 mal e o falso, na certa, não são malignos tanto como o demônio, pois deles se fazem sujeitos particulares (como aliás também do demônio). Como mal e falso, são apenas universais; não obstante têm sua própria essencialidade, um em contraste com o outro" (HEGEL, 2012, p. 48).
Talvez nada diga mais da essência do pensamento dialético do que o fato da autoconsciência do momento subjetivo da verdade, a reflexão da reflexão, deve reconciliar a injustiça que a subjetividade mutiladora causa à verdade apenas ao supor e ao colocar como verdade aquilo que nunca é inteiramente verdadeiro. Se a dialética idealista se volta contra o idealismo, ela o faz por causa de seu próprio princípio, exatamente porque a tensão de sua exigência idealista é ao mesmo tempo anti-idealista. Do ponto de vista do ser em-si da verdade, assim como do ponto de vista da atividade da consciência, a dialética é um processo: o processo é nomeadamente a própria verdade (Ibid., p. 115) ${ }^{17}$.

Retomando o fio da meada, podemos entender a consciência natural como a representação da maneira como o entendimento opera, fixando-se constantemente em relações de identidade - que mais tarde se mostrarão 'falsas'. Nesse sentido, a colocação do absoluto ${ }^{18}$ - vale lembrar que o absoluto hegeliano é resultado - desde o começo não passaria de uma ilusão para tal consciência, deve-se lem-

${ }^{17}$ É bem verdade que esse o movimento é desencadeado pelo próprio sujeito pensante e nesse interim devemos "exprimir o verdadeiro não como substância, mas também, precisamente, como sujeito" (HEGEL,2012, p. 34).

18 "O verdadeiro é o todo. Mas o todo é somente a essência que se implementa através de seu desenvolvimento. Sobre o absoluto, deve-se dizer que é essencialmente resultado: que só no fim é o que é na verdade. Sua natureza consiste justo nisso: em ser algo efetivo, em ser sujeito ou vir-a-ser-de-si-mesmo" (HEGEL, 2012, 36). Aí está uma parte fundamental da crítica adorniana a dialética hegeliana, pois para Adorno: “[...] Hegel escamoteou o momento crítico supremo, a crítica à totalidade, a um infinito dado e conclusivo. Despoticamente, ele então eliminou a barreira, aquilo que é irredutível para a consciência, aquilo de que a filosofia transcendental de Kant tira sua experiência mais profunda, e estipulou uma unidade do conhecimento sem fissuras por meio de suas fissuras; o que tem algo de uma ilusão mítica. [...] A pretensão de saltar sobre o particular por meio do todo se torna ilegítima, pois esse todo não é propriamente, como que a famosa sentença da Fenomenologia, o verdadeiro. A referência afirmativa e assegurada desse todo, como se fosse possível possuí-lo seguramente, é uma ficção" (ADORNO, 2013, p.173). 
brar que em outro momento de sua obra Hegel toma a Fenomenologia como a exposição uma longa exposição da 'ascensão' da consciência fenomênica ao saber absoluto - da ciência da consciência, "que a consciência tem como resultado o conceito da ciência, isto é, o saber puro" (HEGEL, 2011, p. 51). 'Ascensão'19 - talvez o nome seja ruim, já que o desenvolvimento hegeliano não seria nada linear, sendo algo mais próximo de uma trajetória espiralada, visto que a trajetória da consciência que ocorre por meio de negações determinadas, 'superações' e pela rememoração (final) que se daria pela 'passagem' das diversas figuras da consciência, que constantemente fazem a experiência de sua inverdade (em que pese a dialética entre verdade e inverdade já apontada anteriormente e a sua processualidade). Segundo Hyppolite, cada consciência particular, ou figura da consciência, que encontramos no curso do desenvolvimento metodológico, possui uma estrutura própria, que é tanto objetiva, como subjetiva. O "Verdadeiro é um mundo posto como sendo em si" (HYPPOLITE, 2003, p. 39) e com esse Verdadeiro se relaciona um saber, saber desse objeto como em si. Nesse ínterim a consciência - disposta ao desenvolvimento fenomenológico, como ao sofrimento e ao desespero que que lhes são próprios - "põe a prova seu saber para tornálo adequado aquilo que toma como sendo o verdadeiro", contudo com a mudança de seu saber, há também a mudança do objeto, já que este era objeto de um certo saber. Com efeito:

[...] quando a consciência põe à prova o saber que tem de seu objeto, aquilo que tomava como em-si, posto como se fosse o verdadeiro absolu-

\footnotetext{
19 A título de diferenciação, para Freud a consciência estaria sob o signo da conservação: "Façamos agora a fantástica suposição de que Roma não seja uma morada humana, mas uma entidade psíquica com um passado igualmente longo e rico, na qual nada que veio a existir chegou a perecer, na qual, juntamente com a última fase do desenvolvimento, todas as anteriores continuam a viver" (FREUD, 2010, p.23).
}

to, é descoberto como algo que era em si somente para ela. Tal era precisamente o resultado da experiência: a negação do objeto precedente e o aparecimento de um novo objeto, que, por seu turno, dá origem a um novo saber (HYPPOLITE,2003, p. 39).

Eis aí a famigerada experiência ${ }^{20}$, essencial à exposição fenomenológica. Poderíamos mesmo entender a dialética como uma experiência ${ }^{21}$, a não ser por uma questão de 'coordenadas', como gostaria Habermas. Explico: para tal autor as "dimensões do em si, para ela e para nós designam o sistema de coordenadas no qual se desenrola a experiência da reflexão" (HABERMAS, 2014, p. 47)22. Ou seja, na experiência a consciência vê desaparecer o que para ela era tomado como o Verdadeiro e o em si, ao mesmo tempo que vê o objeto que aparece diante dela, como algo novo, um novo mundo. Já para consciência filosófica, ou para nós, "tal objeto (Gegenstand) é engendrado; ela o vê nascer do movimento anterior [...] ao passo que esquece tal passado" (HYPPOLITE, 2003, p.40-41). Chegou-se aqui ao terreno da negação determinada ${ }^{23}$, pois há uma nega-

20 “[...]deve-se dizer que nada é sabido que não esteja na experiência; - ou, como também se exprime a mesma coisa - que não esteja presente como verdade sentida, como Eterno interiormente revelado, como o sagrado em que se crê, ou quaisquer outras expressões que sejam empregadas. Com efeito, a experiência é exatamente isto: que o conteúdo - e ele é o espírito - seja em si substância, e assim, objeto da consciência" (HEGEL, 2012, p.539).

21 "Esse movimento dialético que a consciência exercita em si mesma, tanto em seu saber como em seu objeto, enquanto dele surge um novo objeto verdadeiro para a consciência, é justamente o que se chama experiência." (HEGEL, 2012, p. 80).

22 Ver também os seguintes parágrafos da Fenomenologia: §83, §84 e §85 (HEGEL, 2012, p. 78-80).

23 "Separa-os portanto a distância que aparta a negação determinada da simples negação abstrata, assim caracterizada pela fenomenologia: o ceticismo, desconhecendo a natureza do impulso que comanda seu movimento, 'vê sempre, no resultado, o puro-nada tãosomente, e abstrai do fato de que esse nada é, deter- 
ção da figura, mas não uma negação que leva a um nada abstrato e absoluto e sim a um "nada daquilo que resulta: um resultado que contém o que o saber anterior possui de verdadeiro" (HEGEL, 2012, p. 81). Um passo fundamental da exposição hegeliana e que confere certa necessidade ao movimento da consciência natural, caso contrário romper-seia com o critério da imanência na fenomenologia, já que a única maneira de justificar a relação entre as diversas figuras da consciência até o absoluto seria a existência prévia de um saber absoluto. ${ }^{24}$

Dessa pequena exposição vemos que há uma contenção do que existia de verdadeiro na figura anterior, já negada e posteriormente 'elevada' - vislumbra-se aqui um processo cumulativo, familiar a Bildung e a Meister. $\mathrm{O}$ aspecto metodológico de que se fala é o da Aufhebung - suprassunção no português -, no qual aquilo que era ‘imediato’ é colocado em movimento, transformando-se em um momento, ou, em outras palavras aquilo que era pressuposto passa a ser algo posto na exposição fenomenológica ${ }^{25}$. Um aspecto metodoló-

minadamente, o nada daquilo do qual ele procede'" (ARANTES, 1996, p. 252).

${ }^{24}$ De certa forma poderia se dizer que uma das críticas centrais de Habermas a exposição fenomenológica seria a existência de uma trapaça em relação ao critério da imanência: "Para a filosofia crítica, as coisas se apresentam de maneira diferente. Uma vez que o organon gera o mundo no interior do qual a realidade pode aparecer de maneira geral, ele se limita sempre a desvendar essa realidade sob as condições de seu funcionamento, e não a encobri-la. [...] Porém, sem identificar as condições do conhecimento possível, não poderemos de modo algum falar, sob os pressupostos da filosofia transcendental, de conhecimento em sentido pleno. A crítica de Hegel não procede, portanto, de forma imanente; a objeção contra a teoria do conhecimento como organon já pressupõe o que esta, por sua vez, coloca justamente em questão: a possibilidade do saber absoluto" (HABERMAS, 2014, p.38-39).

${ }^{25}$ Aqui vemos um motivo um tanto quanto mefistofélico em Hegel - lembrando da famosa colocação em Fausto: "O Gênio sou que sempre nega!/E com razão; tudo o que vem a ser /É digno só de perecer" (GOETHE, gico que pode ser melhor acompanhado a partir de outra obra do filósofo:

Superar [Aufheben] e o superado (o ideal) é um dos conceitos mais importantes da filosofia, uma determinação fundamental que pura e simplesmente retorna por todos os lados e cujo sentido tem de ser apreendido de modo determinado e ser particularmente distinguido do nada. - O que se supera, não se torna, por isso, nada. $\mathrm{O}$ nada é o imediato; algo superado, ao contrário, é algo mediado, é o não existente, mas como resultado que partiu de um ser; ele tem, portanto, ainda em si a determinidade da qual procede. [...] O conservar mesmo já implica em si o negativo, ao ser tomado de algo e sua imediaticidade e, assim, de algo são tomados os efeitos exteriores de uma existência aberta, a fim de conservá-lo. - Assim, o superado é algo ao mesmo tempo conservado, que apenas perdeu sua imediaticidade, mas, por isso, não foi aniquilado. - As duas determinações indicadas do superar podem ser apresentadas, em termos lexicais, como dois significados dessa palavra. [...] Algo é apenas superado ao entrar em unidade com o seu oposto; nessa determinação mais precisa, como algo refletido, algo pode ser apropriadamente chamado momento (HEGEL, 2011, p.98).

Seriam esses alguns dos aspectos metodológicos fundamentais da exposição fenomenológica, cujo caminho - como já foi dito anteriormente - irá 'desaguar' no saber absoluto, um saber que nada mais é do que: a rememoração de todas as etapas percorridas - entre o desespero e o sofrimento - pela consciência. Nas palavras de Hegel:

Esse vir-a-ser apresenta um movimento lento e um suceder-se de espíritos, um ao outro; uma galeria de imagens, cada uma das quais, dotada com a riqueza total do espírito, desfila com lentidão justamente porque o Si tem de penetrar e de dirigir toda essa riqueza de sua substância. Enquanto sua perfeição consiste em saber per-

2010, p.139) . Algo já apontado por Adorno: “O princípio goethiano-mefistofélico de que tudo o que existe merece perecer significa em Hegel que a destruição de todo singular é determinada pela sua própria singularização, pela particularidade, a lei do todo [...]" (ADORNO, 2013, p.164). 
feitamente o que ele é - sua substância - esse saber é então seu adentrar-se em si, no qual o espirito abandona seu ser-aí e confia sua figura à rememoração. [...] a re-memoraçãoos conservou; a rememoração é o interior, e, de fato, a forma mais elevada da substância. Portanto, embora esse espírito recomece desde o princípio sua formação, parece partir somente de si, ao mesmo tempo é de um nível mais alto que [re]começa. [...] O reino-dos-espíritos, que desse modo se forma no ser-aí, constitui uma sucessão na qual um espírito sucedeu a um outro, e cada um assumiu de seu antecessor o reino do mundo. Sua meta é a revelação da profundeza, e essa é o conceito absoluto. [...] A meta - o saber absoluto, ou o espírito que se sabe como espírito - tem por seu caminho a rememoração dos espíritos como são neles mesmos, e como desempenham a organização de seu reino (HEGEL, 2012, p. 544-545).

\section{Ou como diz Habermas:}

[...] a gênese, que parte da consciência natural, precisa ser reconstruída até chegar ao ponto de vista que o expectador fenomenológico adotara provisoriamente; depois, a posição da crítica do conhecimento pode coincidir com a consciência de si constituída de uma consciência que se inteirou de seu processo de formação, purificando-se assim de elementos contingentes. O sujeito da certificação a ser operada pela crítica do conhecimento não está como que pronto para o chamado da consciência que quer ir diretamente ao exame; ele só é dado a si mesmo com o resultado de uma autocertificação (HABERMAS, 2014, p. 44-45).

Com isso colocado voltamos ao Meister e seus anos de formação. Uma formação que operaria de maneira análoga à consciência natural em direção ao saber absoluto, nos seus recuos e reviravoltas - à maneira de uma espiral -, além de seu sofrimento e desespero em relação a não verdade da posição anterior ${ }^{26}$. Pro-

26 Judith Butler mesmo considera a Fenomenologia um romance de formação otimista. Nas suas palavras: "After all, the Phenomenology of Spirit is a Bildungsroman, an optimistic narrative of adventure and edification, a pilgrimage of the spirit, and upon immediate scrutiny, it is unclear how Hegel's narrative structure argues the cesso muito bem notado por Mazzari: "O fato, contudo, de que [...] o herói mergulhe numa crise tão mais profunda mostra apenas que o complexo processo formativo configurado no romance se dá de maneira descontínua, marcada tanto por avanços como por recuos e revezes" (MAZZARI, 2012, p. 20). Um episódio emblemático do processo cumulativo de Meister é o abandono do teatro, quando faz a experiência de sua inverdade como meio que lhe propiciaria uma formação total, novamente ficamos à sombra de Mazzari:

$\mathrm{Na}$ medida em que avança a sua compreensão das relações sociais e o processo de autoconsciência, o jovem herói vai também se distanciando do teatro. O ponto de viragem ocorre paradoxalmente no Livro $\mathrm{V}$, quando sua carreira atinge, com a encenação do Hamlet, o ápice. Torna-se-lhe claro, após brilhante performance, que o teatro por si só não é capaz de oferecerlhe respostas em sua busca, pois se subordina a um complexo que envolve ampla gama de valores humanistas. Wilhelm compreende ao mesmo tempo que o entusiasmo pelo palco sempre esteve intrinsecamente relacionado à rejeição pelas formas de vida burguesa que lhe estavam determinadas. Conscientiza-se de que em todos os papéis que representasse ele estaria, no fundo, representando a si mesmo, como diletante. Desse modo, revela-se que a opção pelo teatro não foi senão um equivoco, mas ao mesmo tempo torna-se-lhe igualmente claro que este equivoco, representou uma etapa essencial em sua trajetória. Sofrendo Wilhelm todas as consequências desse erro para depois, na etapa seguinte, superá-lo de maneira consciente, o desenvolvimento ruma à nova concepção de formação humanista realiza um avanço objetivo e definitivo (Ibid., p. 17, grifos meus).

Salta aos olhos as semelhanças da experiência formativa de Meister e a experiência da inverdade das figuras da consciência, trazidas à luz via Hyppolite. Para além disso há um processo de rememoração, do nosso protagonista, das fases que foram experenciadas em sua incompletude, mas que foram essenciais à formação

metaphysical case he wants to make" (BUTLER, 1999, p.17). 
total tão almejada pela personagem - veja-se a carta endereçada a Werner (GOETHE, 2012, p. 284-287). Rememoração de todas as etapas, ou melhor, de todas as figuras da consciência, que representa o saber absoluto - como exposto anteriormente.

Há ainda um outro ponto sobre formação e método que resta mostrar - como diz Arantes "se nos for permitido lançar mão da sobrecarga de sentido de termo Bildung, pedra de toque do edifício fenomenológico" (ARANTES, 1996, p. 253). Voltando a Gadamer, vemos que uma de suas lições é o fato de que a "essência do trabalho é formar a coisa, e não deformá-la” (GADAMER, 2013, p. 48). Nesse ínterim do trabalho a consciência laboriosa cultiva-se, ou - no dialeto dos espíritos cultos em realidades atrasadas - forma-se.

Em meio a trama do livro de Hegel, deparamo-nos com uma luta de vida ou morte na verdade esse último destino não pode se concretizar, visto que, como será mostrado, só uma consciência 'viva' pode reconhecer a outra - por reconhecimento entre duas consciências - paradoxalmente ensejada por um desejo egoísta 27 . Dessa luta temos como resultado: uma consciência que é escravizada por uma consciência que passa a ser senhor, daí saltamos para a conhecida dialética do senhor e do escravo ${ }^{28}$, ou, mais especificamente, o Silogismo da Dominação. Um silogismo que consiste: "[...] no fato de o senhor colocar o escravo entre si e a natureza. O escravo é o termo médio através do qual o senhor se relaciona com a natureza. Isto produz uma desigualdade entre o trabalho e o gozo (Genuss) ou uma ausência de simetria entre o produtor e o consumidor" (SANTOS, 1993, p. 90). Um

${ }^{27}$ Cf. HEGEL (2012, p. 135 - 151) (2011, p.197-206).

28 "Nisso se sugere exatamente aquele tipo de astúcia, algo como uma grandiosa artimanha camponesa, por tanto tempo ensinada, de se esconder sob os poderosos e se apoiar em suas necessidades até que se possa tomar deles o poder: a dialética do senhor e do escravo da Fenomenologia deixa escapar esse segredo" (ADORNO, 2013, p. 122). silogismo que se pode acompanhar com o seguinte esquema:

(a) O senhor se relaciona com a natureza mediante o trabalho do escravo. (b) Este está preso à natureza (é sua cadeia), transformando seu lado áspero (a matéria prima) em utensílio e bens de consumo, que o senhor consome sem esforço. (c) Por conseguinte, o senhor se relaciona consigo mesmo mediante o escravo, pois dele depende para consumir. (d) O senhor se relaciona com a natureza mediante o escravo, pois o que ele consome é a natureza transformada pelo trabalho escravo. Por sua vez, (e) o escravo se relaciona diretamente com a natureza bruta e a transforma pelo trabalho. Mas como neste silogismo ele foi subsumido no senhor, sua relação com a natureza passa antes pela submissão ao senhor. (f) Isto quer dizer que o escravo é obrigado a trabalhar e que o produto do trabalho pertence ao senhor. Em outras palavras, o escravo depende do senhor também para consumir, só lhe sendo dado consumir o que o senhor permite, o suficiente para mantê-lo vivo. Isto explica a definição de trabalho como desejo reprimido e consumo retardado: o senhor, que está entre o escravo e a natureza, só lhe concede satisfazer o desejo de consumo sob medida, retardando assim o desaparecimento do objeto, que pode então ser entesourado (Ibid., p.91).

O senhor passa assim a realizar o puro desfrute da coisa sem trabalhar, "o seu desejo é a pura negação do objeto, consumo imediato" (Ibid., p. 95); já o escravo tem o seu desejo reprimido tendo que adiar o consumo da coisa: o "trabalho, ao contrário, é desejo refreado, um desvanecer contido, ou seja, o trabalho forma" (HEGEL, 2012, p. 150). Mas é essa servidão mesma que levaria a liberdade, ou melhor, os "passos da libertação se consumam na disciplina do servir e no trabalho sobre a natureza, que completam a experiência de sua formação" (SANTOS, 1993, p. 95). Do ponto de vista do reconhecimento, mais especificamente na visão do senhor, dá-se um verdadeiro impasse existencial - acompanhando Kojève: 
A relação entre senhor e escravo não é portanto um reconhecimento propriamente dito. [...] $\mathrm{O}$ senhor não é o único a se considerar como senhor. O escravo também o considera como tal. Logo, o senhor é reconhecido em sua realidade e sua dignidade humanas. Mas esse reconhecimento é unilateral, porque ele não reconhece a realidade e a dignidade humanas. Logo, ele é reconhecido por alguém que ele não reconhece. $\mathrm{E}$ nisso está a insuficiência - e o caráter trágico de sua situação. O senhor lutou e arriscou a vida pelo reconhecimento, mas só obteve um reconhecimento sem valor para si. Porque ele só pode ficar satisfeito com o reconhecimento por parte de quem ele reconhece como alguém digno de o reconhecer. A atitude do senhor é pois um impasse existencial. De um lado, o senhor só é senhor porque seu desejo buscou não uma coisa, mas um outro desejo, foi um desejo de reconhecimento. De outro lado, como se tornou senhor, como senhor deve desejar ser reconhecido; e só pode ser reconhecido como tal fazendo do outro seu escravo. Mas o escravo é para ele um animal ou uma coisa. Logo, ele é reconhecido por uma coisa. Assim, no final das contas, seu desejo busca uma coisa e não - como parecia no início - um desejo (humano). O senhor se enganou (KOJĖVE, 2014, p. 23).

No desenvolvimento dessa relação o silogismo da dominação se inverte e o senhor passa a depender do escravo:

O senhor consome como animal, sem precisar trabalhar [...], daí sua desumanidade, que se satisfaz no apetite voraz [...]. O escravo se formou na disciplina e, ao transformar a natureza bruta, ao desenvolver o domínio da coisa, se formou a si mesmo, se educou. Pois não é possivel transformar a natureza, sem se transformar, sem torna-se cultivado. [...] A situação se inverteu, não pela revolta do escravo que logra êxito ao se insurgir contra o senhor, mas pela educação de si mesmo. [...] A pedagogia de Hegel é uma pedagogia do trabalho e da disciplina: a verdadeira transformação do mundo está no trabalho e na educação pelo trabalho (SANTOS, 1993, p. 96, grifos meus).

É no trabalho que a consciência escrava passa a encontrar a si mesma, não sendo mais algo estranho a ela. Para tal encontro, Santos lembra de dois momentos que são fundamen- tais: "o momento do medo ${ }^{29}$ e do serviço em geral, assim como o momento da formação". E nenhum deles pode se dar sem o outro, pois sem a disciplina do serviço, o medo seria formal; sem a formação, o medo seria apenas interior; sem medo, a consciência se desenvolve em um sentido vão "finalmente, se não estivesse exposta ao medo absoluto, a essência negativa permaneceria sempre algo exterior à consciência. Em resumo, se faltasse um desses elementos, a consciência servil não lograria dominar o poder universal e a essência objetiva em sua totalidade" (Ibid., p. 97). Ao tornarse senhor da natureza pela via do trabalho, forma-se, fazendo-se senhor de si mesmo; suprimindo, assim, aquela escravidão a que havia sido submetido.

Em suma, aquela pedra de toque para o edifício fenomenológico - de que falava Arantes -, apresenta-se aqui como um 'episódio' fundamental da exposição hegeliana - ela mesma uma espécie de formação, como havíamos dito anteriormente -, imbricando-se. Um episódio sem o qual não chegaríamos ao Espírito, visto que:

[...] a Odisséia da consciência servil se prolonga na consciência estóica, que assinala, em linhas gerais, o fim do mundo antigo. É sintomático que na consciência infeliz se unam o senhor, na figura do imperador Marco Aurélio, e o escravo, representado por Epitecto, ambos estóicos em sua atitude de dependência diante do Destino. Mas a formação do homem não termina com o ceticismo nem com o puro conformismo; a consciência - de -si abre o caminho para o ca-

29 “Ou seja, essa consciência servil sentiu medo não disto ou daquilo, não durante este ou aquele momento, mas de toda a sua [própria] realidade-essencial. Porque ela sentiu a angústia da morte, do senhor absoluto. Nessa angústia, a consciência servil foi interiormente dissolvida; toda ela estremeceu, e nela tudo o - que - é - fixo - e - estável tremeu. Ora, esse movimento [dialético] universal puro, essa liquefação absoluta de toda posição-estável é a realidade-essencial simples-ou-indivisa da consciência-de-si, a negatividade - negadora absoluta, o Ser-para-si puro" (KOJÉVE, 2014, p. 25, grifos meus). 
pítulo da Razão e depois para o capítulo do Espírito (Ibid., p. 98).

\section{5 À GUISA dE CONCLUSÃo, CON- SIDERAÇÕES FINAIS}

De posse do que até fora exposto, é possível notar uma semelhança entre a forma do romance de formação goethiano e a forma da fenomenologia do espírito hegeliana, mostrando-se uma profunda solidariedade entre Bildung, método e forma literária. A formação de Meister, bem como os caminhos difíceis da consciência e suas figurações em direção ao saber absoluto, operariam de modo homólogo, em suas reviravoltas e recuos, além de seu desespero ou sofrimento frente à inverdade da posição anteriormente tomada como a verdadeira.

Solidariedade a qual nos permitiria indagar - tendo em vista alguns fragmentos já deixados ao longo do artigo, em rodapés, por exemplo - se, ao fim e ao cabo, a formação histórica e social alemã dotada de seu atraso relativo frente à sociedade francesa (ARANTES, 1996; LUKÁCS, 1959), por exemplo, não teria deixado de ser apenas fundo dessas reflexões e passasse a ser figura? Em outras palavras, o atraso alemão com os nossos autores não teria deixado, para falar com Schwarz (2012, p. 129-157), de ser mero dado externo e se tornado mola propulsora do pensamento de ambos (ARANTES, 2004, p.271-273)? Por hora fecharemos apenas com estas perguntas, até porque desdobrar o que será aqui colocado nos levaria a outro projeto de pesquisa e a constituição de um novo artigo, ou melhor, uma série de novos textos.

\section{BIBLIOGRAFIA}

ADORNO, T. W. Notas de literatura I. São Paulo: Duas Cidades; Editora 34, 2012.

ADORNO, T. W. Três estudos sobre Hegel. São Paulo: Editora Unesp, 2013.

ARANTES, P. Ressentimento da dialética.
São Paulo: Paz e Terra, 1996.

ARANTES, P. Zero à esquerda. São Paulo: Conrad, 2004.

AUERBACH, E. Mimesis. $\sigma^{\mathrm{a}}$ edição. São Paulo: Perspectiva, 2013.

BUTLER, J. Subjects of desire: Hegelian Reflections in Twentieth - Century France. New York: Columbia University Press, 1999.

DESCARTES, R. Discurso do Método. São Paulo: Ed. WMF Martins Fontes, 2009.

ECKERMANN, J. P. Conversação com Goethe nos últimos anos de sua vida: 1823-1832. São Paulo: Editora Unesp, 2016.

FAUSTO, R. Entre Adorno e Lukács (Dois livros de Paulo Arantes). Lua Nova. São Paulo, v. 1, no 47, p. 201-220, set.-dez.,1997. https://doi.org/10.1590/S0102-64451997000300008

FREUD, S. Obras Completas (vol.18). São Paulo: Companhia das Letras, 2010.

FICHTE, J. G. Sobre o conceito da doutrinada-ciência ou da assim chamada filosofia. In: TORRES FILHO, R. R. Os Pensadores(col.), vol. XXVI. São Paulo: Abril Cultural, 1973, p. 15-39.

GADAMER, H.-G. Verdade e Método I: traços fundamentais de uma hermenêutica filosófica. $8^{a}$ edição. Petrópolis, RJ; Bragança Paulista, SP: Vozes; Editora Universitárias São Francisco, 2013.

GOETHE, J. W. V. Fausto: uma tragédia Primeira parte. $6^{a}$ edição. São Paulo: Editora 34, 2010.

GOETHE, J. W. V. Os anos de aprendizado de Wilhelm Meister. $2^{\mathrm{a}}$ edição. São Paulo: Editora 34, 2012.

HABERMAS, J. Conhecimento e interesse. São Paulo: Editora Unesp, 2014.

HEGEL, G. W. F. Ciência da lógica: (excertos). São Paulo: Barcarolla, 2011.

HEGEL, G. W. F. Cursos de estética, volume II. São Paulo: EDUSP, 2014.

HEGEL, G. W. F. Cursos de estética, volume IV. São Paulo: EDUSP, 2004.

HEGEL, G. W. F. Enciclopédia das ciências filosóficas em compêndio (1830): A Filosofia do Espírito (vol. III). São Paulo: 
Edições Loyola, 2011.

HEGEL, G. W. F. Fenomenologia do Espírito. $8^{a}$ edição. Petrópolis: Vozes, 2012.

HYPPOLITE, J. Gênese e Estrutura da Fenomenologia do Espírito de Hegel. $2^{\mathrm{a}}$ edição. São Paulo: Discurso, 2003.

KANT, I. Resposta à pergunta: O que é esclarecimento?. In: KANT, I et al. O que é Esclarecimento?. Rio de Janeiro: Via Verita, 2011, p. 23-37.

KOJËVE, A. Introdução à leitura de Hegel. Rio de Janeiro: Contraponto, 2014.

LUKÁCS, G. A teoria do romance. $2^{a}$ edição. São Paulo: Duas Cidades; Editora 34, 2009.

LUKÁCS, G. El assalto alarázon. México. D.F.: Fondo de Cultura Económica, 1959.

MAAS, W. P. M. D. O cânone mínimo: o Bildungsroman na história da literatura. São Paulo: Editora Unesp, 2000.

MARX, K. Crítica da filosofia do direito de Hegel. 2a edição. São Paulo: Boitempo, 2011.

MARX, K. O capital: crítica da economia política. Vol.1, Tomo 2. São Paulo: Nova Cultural, 1985.

MAZZARI, M. V. Apresentação. In: GOETHE, J. W. V. Os anos de aprendizado de Wilhelm Meister. 2a edição. São Paulo: Editora 34, 2012, 7-27.

MAZZARI, M. V. Labirintos da aprendizagem: Pacto fáustico, romance de formação e outros temas de literatura comparada. São Paulo: Editora 34, 2010.

MELDELSSOHN, M. Sobre a Pergunta: o que quer dizer esclarecer? In: KANT, I et al. O que é Esclarecimento?. Rio de Janeiro: Via Verita, 2011, 15-23.

MÜLLER, M. L. Exposição e método dialético em 'O Capital'. Boletim SEAF - MG. Belo Horizonte, v. 2, n. 1, p. 17-41, jul.-dez., 1982.

PATO, C. G. O discurso Econômico da Modernidade: notas da periferia. 2011. 93p. Tese (Doutorado em Filosofia). Curso de Filosofia, Faculdade de Filosofia, Letras e Ciências Humanas, USP, São Paulo, 2011.
PRADO JR, B. Prefácio. In: ARANTES, P. Ressentimento da dialética. São Paulo: Paz e Terra, 1996.

SANTOS, J. H. Trabalho e riqueza na Fenomenologia do espírito de Hegel. São Paulo: Loyola, 1993.

SCHELLING, F. V. Exposição da ideia universal da filosofia em geral e da filosofia - da natureza como parte integrante da primeira. In: TORRES FILHO, R. R. Os Pensadores(col.), vol. XXVI. São Paulo: Abril Cultural, 1973, p. 213-225.

SCHWARZ, Roberto. Que horas são?. $2^{\mathrm{a}}$ ed. São Paulo: Companhia das Letras, 2012.

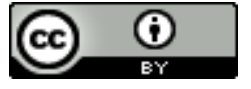

License information: This is an openaccess article distributed under the terms of the Creative Commons Attribution License, which permits unrestricted use, distribution, and reproduction in any medium, provided the original work is properly cited.

Artigo recebido em 05 de abril de 2019.

Avaliado em 11 de outubro de 2019.

Aceito em 31 de outubro de 2019.

Publicado em 21 de novembro de 2019.

Como citar este artigo (ABNT):

MARINO, Rafael. Bildung e método: notas sobre Hegel e Goethe. Estação Científica (UNIFAP), Macapá, v. 9, n. 2, p. 87-102, abr./jun. 2019. 